ARTICLE

https://doi.org/10.1038/s41467-019-13152-y

\title{
Transcription and translation contribute to gene locus relocation to the nucleoid periphery in E. coli
}

Sora Yang ${ }^{1,5}$, Seunghyeon Kim²,5, Dong-Kyun Kim (10 ${ }^{3}$, Hyeong Jeon An² ${ }^{2}$ Jung Bae Son ${ }^{1}$, Arvid Hedén Gynnå ${ }^{4} \&$ Nam Ki Lee (iD ${ }^{1 *}$

Transcription by RNA polymerase (RNAP) is coupled with translation in bacteria. Here, we observe the dynamics of transcription and subcellular localization of a specific gene locus (encoding a non-membrane protein) in living E. coli cells at subdiffraction-limit resolution. The movement of the gene locus to the nucleoid periphery correlates with transcription, driven by either E. coli RNAP or T7 RNAP, and the effect is potentiated by translation.

\footnotetext{
${ }^{1}$ Department of Chemistry, Seoul National University, Seoul 08826, Korea. ${ }^{2}$ Department of Physics, Pohang University of Science and Technology, Pohang 37673, Korea. ${ }^{3}$ School of Interdisciplinary Bioscience and Bioengineering, Pohang University of Science and Technology, Pohang 37673, Korea. ${ }^{4}$ Department of Cell and Molecular Biology, Uppsala University, 75236 Uppsala, Sweden. ${ }^{5}$ These authors contributed equally: Sora Yang, Seunghyeon Kim.

*email: namkilee@snu.ac.kr
} 
T ranscription, the process by which mRNA is generated from DNA, is one of the most fundamental processes in cells and has been extensively studied using X-ray crystallography ${ }^{1,2}$, bulk biochemical assays ${ }^{3}$, and singlemolecule experiments ${ }^{4-10}$. Much of the knowledge of transcription has been derived from in vitro studies, in which purified RNA polymerases (RNAPs) and relatively short DNAs have been used at dilute concentrations in isolation from other machinery proteins. However, the environment in a living cell is quite different from in vitro conditions. The complex structure of the nucleoid and the active reactions of other proteins, such as DNA polymerases, other RNAPs, and ribosomes, on the same DNA and mRNA molecules may affect transcription reactions in living cells ${ }^{11}$. One interesting example of these effects is that transcription is highly coupled with translation in that RNAP is followed immediately by ribosomes ${ }^{12}$. Recent studies have shown that transcription-translation coupling is more complicated than previously thought; the transcriptional rate is determined by the translational rate via direct interactions between RNAP and ribosomes ${ }^{13-18}$. However, fluorescence imaging studies have shown that RNAPs and ribosomes are located mainly in different subcellular regions in bacterial cells, i.e., RNAPs localize to the nucleoid area, while ribosomes localize outside nucleoids ${ }^{19,20}$. Thus, how transcription and translation are spatially coupled in bacterial cells remains unclear ${ }^{21,22}$. It is well known that Escherichia coli (E. coli) RNAPs form distinct foci located at the nucleoid periphery under fast growth conditions ${ }^{20,22,23}$. These foci have been suggested to actively transcribe genes, such as $r r n$ operons $s^{20,23,24}$. However, it has not been directly proven whether gene loci located at the nucleoid periphery are highly transcribed by RNAPs or gene loci located inside the nucleoid move to the nucleoid periphery due to transcription ${ }^{23}$.

Transcription in living cells has been investigated by visualizing single mRNA molecules ${ }^{25,26}$ and detecting mRNA production in real time 27,28 . In addition, the localization ${ }^{20,24,29}$ and tracking ${ }^{23,30}$ of RNAPs were achieved using fluorescent protein (FP)-tagged RNAPs in live E. coli cells. To study in vivo transcription at the single-protein level, RNAP fused with FP has to be maintained at a low copy number ${ }^{31-33}$. More importantly, the E. coli genome contains thousands of promoters to which RNAPs can bind, which makes it nearly impossible to visualize the location of a specific gene locus occupied by RNAPs ${ }^{23}$.

Here, we report the direct observation that the subcellular location of a non-membrane protein's gene locus under transcription moves to the nucleoid periphery (or toward the plasma membrane), an area known as the ribosome-rich region. To overcome the limitation of using FP-tagged endogenous E. coli RNAP, we use T7 RNAP fused with enhanced yellow fluorescent protein (eYFP) and inserted one copy of the T7 RNAP-specific promotor in the E. coli genome ${ }^{34}$. Using this system, we directly observe T7 RNAP actively transcribing a specific gene at the single-molecule level in living cells. We also use a method of marking the location of a gene using DNAbinding proteins ${ }^{35,36}$ to observe the location of a specific gene locus during transcription by E. coli RNAP. We show that the subcellular relocation of gene loci is a general phenomenon that occurs during transcription by both E. coli RNAP and T7 RNAP in E. coli cells. Using T7 RNAP transcription system that is uncoupled with translation, we demonstrate that two factors are involved in gene locus movement during transcription and responsible for the relocation of gene loci during transcription to the nucleoid periphery: transcriptional activity and ribosome binding to mRNAs. When transcription by endogenous E. coli RNAP is coupled with translation by ribosome, however, the degree of relocation of gene locus is significantly enhanced.

\section{Results}

Localization of gene loci actively transcribed by T7 RNAP. In order to visualize the location of a specific gene locus occupied by RNAPs, we replaced the endogenous promoter of the lac operon with a T7 RNAP-specific promoter (Fig. 1a). T7 RNAP is a singlesubunit enzyme that performs all transcription reactions, like multisubunit RNAPs $1,37,38$. T7 RNAP was expressed from the plasmid pNL003 (inducer, L-rhamnose). We achieved an expression level of $\sim 35$ copies of eYFP-T7 RNAP to detect diffraction-limited spots in a cell (Supplementary Fig. 1). Two lac operators (O1) were placed up- and downstream of the T7 promoter $^{31}$, which tightly suppressed expression by T7 RNAP in the absence of the inducer isopropyl- $\beta$-D-1-thiogalactopyranoside (IPTG) (Fig. 1a). No localized fluorescent spots of eYFP-T7 RNAP were detected in the absence of IPTG, i.e., transcription was blocked (Fig. 1b). However, after the addition of $1 \mathrm{mM}$ IPTG, which induces the dissociation of LacI from the operator sites, eYFP-T7 RNAPs were able to bind the T7 promoters and transcribe downstream of the promoters. Indeed, T7 RNAPs actively transcribing the gene were detected as diffraction-limited spots in a cell (Fig. 1c). Each cell typically contained one or two foci depending on its cell cycle. This new transcription imaging system allowed us to probe the subcellular locations of only actively transcribing RNAPs and a specific gene locus in a living E. coli cell.

Direct measurement of the elongation rate of T7 RNAP in cell. The diffraction-limited fluorescent spots indicated the location of T7 RNAPs transcribing downstream of the inserted T7 promoter (Fig. 1c). To confirm that the fluorescent foci shown in Fig. 1c indicate the locations of genes actively transcribed by T7 RNAPs, we measured the elongation kinetics of T7 RNAP using fluorescent imaging. A simple kinetic model was used to describe the transcriptional kinetics (Fig. 1d); $k_{\text {on }}$ denotes the transcriptional on-rate, which includes promoter searching by RNAPs, RNAPpromoter complex formation, and transcription initiation, and $k_{\text {off }}$ is the transcriptional off-rate, which is determined by the elongation duration time, i.e., the time an RNAP spends as it moves from the promoter site to the terminator site. These transcriptional kinetic parameters can be derived from the appearance of fluorescent foci and an increase in their intensity, which represents the number of T7 RNAPs transcribing genes per cell as a function of time after IPTG addition (Fig. le and Supplementary Note 1). Gene length was controlled by inserting tandem T7-specific termination sites downstream of lacY (Fig. 1a), which resulted in a gene length of $\sim 4.5$ kilo-base pairs (kbps) (strain T7p_4.5kb). We fit the data of T7p_4.5kb with a 4.5-kbp gene length using the kinetic model (Fig. 1e, blue) and obtained $k_{\text {on }}\left(0.46 \pm 0.03 \mathrm{~min}^{-1}\right.$, mean \pm standard deviation $)$ and $k_{\text {off }}\left(1.12 \pm 0.11 \mathrm{~min}^{-1}\right)$. Considering that the elongation duration time, which is longer than tenths of a second, is much longer than the transcription termination time ${ }^{39}$, we obtained the elongation rate $\left(4.5 \mathrm{kbp} \times k_{\text {off }}\right)$, which was $84 \pm 8 \mathrm{bp} \mathrm{s}^{-1} .1 / k_{\mathrm{on}}$, which was $131 \pm 10 \mathrm{~s}$, denotes the average time for T7 RNAPs to get into an elongation state after their repeated attempts to find the promoter and initiate transcription.

Then, as a control, we shortened the gene length to $3.3 \mathrm{kbp}$ by placing termination sites at the end of the lac $Z$ gene (T7p_3.3kb). We expected that the elongation rate and transcription initiation rate would be invariant, while the elongation duration time would be reduced by the shortened gene length. Indeed, the elongation time was reduced to $36 \pm 3 \mathrm{~s}$ (T7p_3.3kb) from $54 \pm 6 \mathrm{~s}$ (T7p_4.5kb), but the elongation rate and $1 / k_{\mathrm{on}}$, which were $92 \pm 7 \mathrm{bp} \mathrm{s}^{-1}$ and $149 \pm 14 \mathrm{~s}$, respectively (Fig. le, red), were similar to those of $\mathrm{T} 7 \mathrm{p} \_4.5 \mathrm{~kb}$. These results demonstrate the 


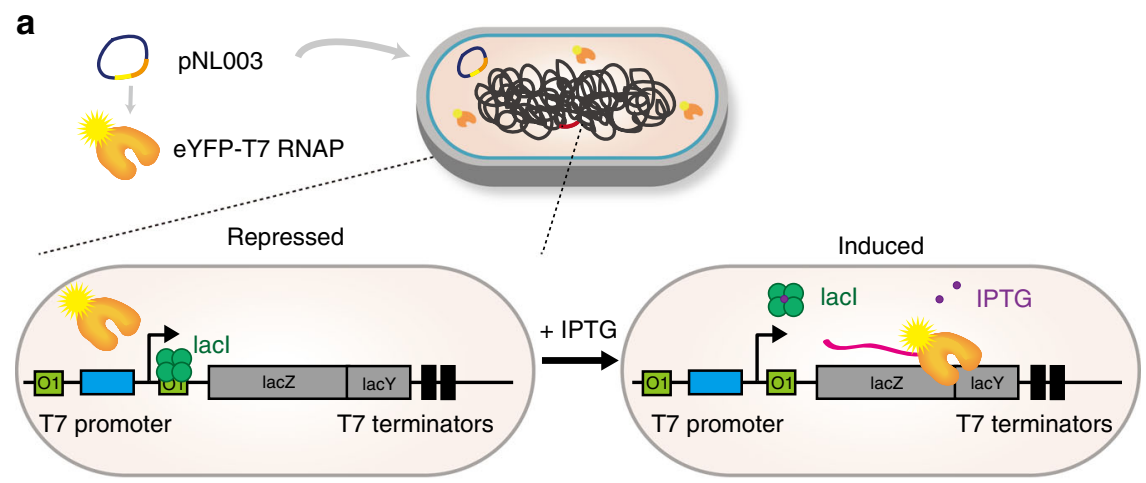

b

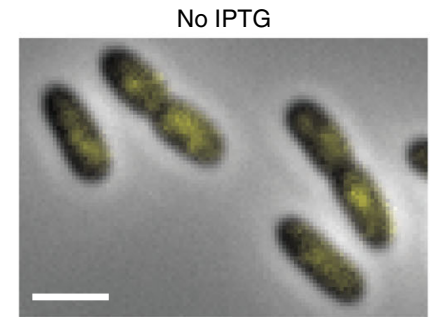

d

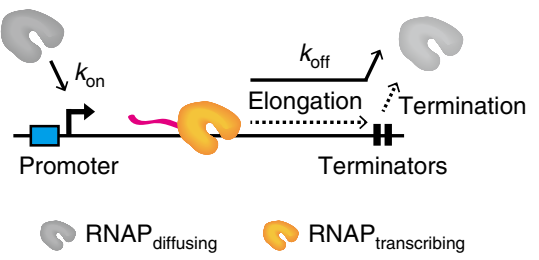

c

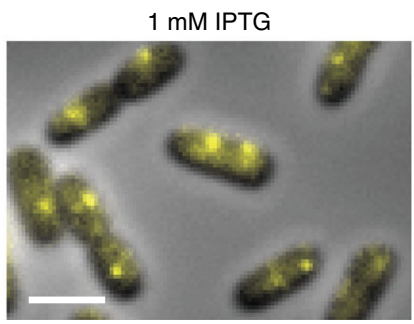

e

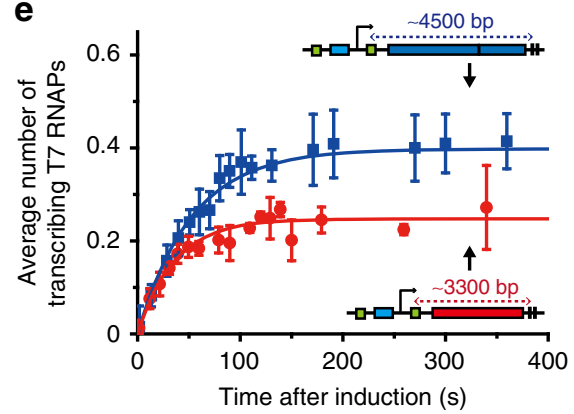

Fig. 1 Transcription by T7 RNAP in living E. coli cells was observed by single-protein detection. a A schematic illustration of the gene system used to visualize single eYFP-T7 RNAPs during transcription. eYFP-T7 RNAP is expressed from an L-rhamnose inducible plasmid (pNL003). The left panel represents the repressed condition, in which the binding of Lacl proteins on two Lac operators (O1) blocks transcription by RNAP. The right panel represents the induced condition, in which Lacl proteins dissociate from their operators with the addition of 1 mM IPTG and RNAP thus binds to the T7 promoter and generates mRNAs. b, c Representative images of eYFP-T7 RNAPs in E. coli cells. Scale bar, $2 \mu$ m. b No IPTG. Blurred fluorescent signals from the rapidly diffusing eYFP-T7 RNAP molecules were detected. c With $1 \mathrm{mM}$ IPTG. The image was acquired at $303 \mathrm{~s}$ after adding IPTG. Diffraction-limited fluorescent foci of eYFP-T7 RNAP were clearly observed. $\mathbf{d}$ A kinetic model of in vivo transcription. $k_{\text {on }}$ denotes the transcriptional on-rate, and $k_{\text {off }}$ denotes the transcriptional off-rate (Supplementary Note 1). e Average number of transcribing eYFP-T7 RNAPs during transcription per cell after IPTG induction, including cells that exhibit no bright spots. The blue filled squares and the red filled circles denote data from the induction of the T7p_4.5 kb and T7p_3.3 kb strains, respectively. The data were fitted to a single exponential function, $a(1-\exp (-b t))$, where $a=k_{\text {on }}^{\prime} \times\left[R^{\prime} P_{\text {total }}\right] / k_{\text {off }}$ and $b=k_{\text {off. }}$ The elongation rate of RNAP equals $L_{\text {gene length }} \times k_{\text {off }}$. The average total number of T7 RNAPs, [RNAP total , in a cell was 35 . The data represent mean $\pm s . d$. (standard deviation) obtained from three independent experiments

robustness of our measurement of the transcription on-rate $\left(k_{\mathrm{on}}\right)$ and off-rate $\left(k_{\text {off }}\right)$, i.e., the elongation rate. To reconfirm the elongation rates measured by image analysis shown in Fig. 1d, e, we determined the elongation rate based on real-time reversetranscription polymerase chain reaction (RT-PCR). To probe the elongation rates in both the T7p_4.5kb and T7p_3.3kb strains, we designed two TaqMan probes to detect the fluorescent signals from probes complementary to the segments of the lac $Z$ transcript (Supplementary Fig. 2). The elongation rates measured by RT-PCR were $101 \pm 7$ and $91 \pm 12 \mathrm{bp} \mathrm{s}^{-1}$ for the T7p_4.5kb and $\mathrm{T} 7 \mathrm{p} \_3.3 \mathrm{~kb}$ strains, respectively, which are consistent with the results of image analysis shown in Fig. 1. It is possible that the average number of transcribing T7 RNAPs in Fig. 1e was underestimated due to the photobleaching effect.

These results confirm that the fluorescent foci in Fig. 1c indicate T7 RNAPs actively transcribing genes. The time- dependent analysis of T7 RNAP fluorescent foci provides an excellent method to probe transcriptional kinetics in living cells. We determined that the elongation rate of T7 RNAP in live E. coli cells in a M9 minimal medium at room temperature is $\sim 90 \mathrm{bp} \mathrm{s}^{-1}$.

Transcription by T7 RNAP induces the relocation of gene loci. Next, we analyzed the localization of transcribing genes using fluorescent foci of T7 RNAP (Fig. 2). A bacterial chromosome is highly condensed and forms a unique structure, the nucleoid, in the center of the cell ${ }^{40}$, as the genome is compacted to fit into a small occupied region in an E. coli cell ${ }^{36,41}$. Thus, the subcellular positions of eYFP-T7 RNAP foci were expected to be mainly localized at the central region of the cell. Interestingly, we often observed localization of the fluorescent foci close to the plasma 

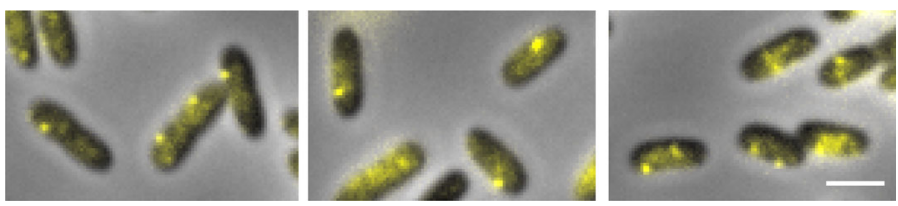

b
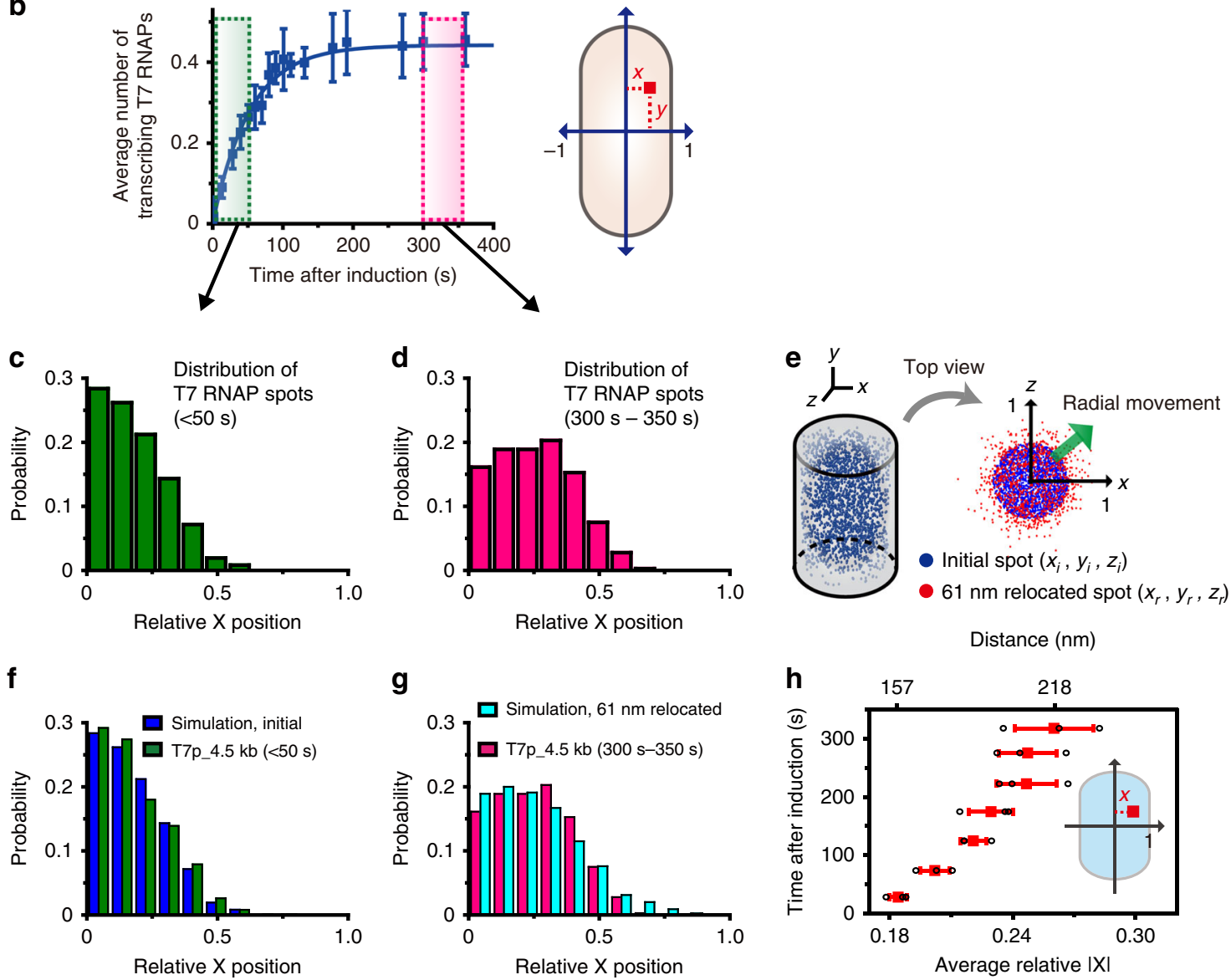

Fig. 2 Gene locus moves to the nucleoid periphery by T7 RNAP-driven transcription. a Representative images of T7p_4.5kb cells acquired late ( $>270 \mathrm{~s}$ ) after adding IPTG. Fluorescent foci denote the locations of gene loci actively transcribed by T7 RNAP. Scale bar, $2 \mu \mathrm{m}$. b Analysis of the subcellular localization of gene locus under transcription. Left panel of $\mathbf{b}$ is a reproduction of Fig. 1e, blue line, for convenience. The green box indicates the time window for the cells at the initial transcription stage, $<50 \mathrm{~s}$. The purple box indicates the time window for the cells between 300 and $350 \mathrm{~s}$ after IPTG induction. The right panel in $\mathbf{b}$ shows normalization of the cell size. The location of each fluorescent spot was determined as relative coordinates $(x, y)$ to take into account differences in cell size. The $\mathrm{x}$-axis corresponds to the short axis of the cell. $\mathbf{c}$, $\mathbf{d}$ Distributions of the subcellular localization of transcribing eYFP-T7 RNAP foci along the short axis. c The distribution of the locations of transcribing RNAP spots within $50 \mathrm{~s}$ after induction (total of 363 fluorescent foci). d The distribution of the locations of transcribing RNAP spots between 300 and $350 \mathrm{~s}$ after induction (total of 360 fluorescent foci). e Simulation of gene loci movements. A total of 100,000 random spots with a 70-nm localization error were generated in the cylindrical coordinates (blue spots). Red spots indicate the final locations of each spot randomly moved in the radial direction by $61 \mathrm{~nm}$ on average. $\mathbf{f}, \mathbf{g}$ Comparison of the simulated and experimental results. $\mathbf{f}$ The distribution obtained by the simulation (blue bar) was similar to the distribution of the initial transcription stage (green bar, same as Fig. 2c). $\mathbf{g}$ The spots obtained by the simulation in Fig. 2e were randomly moved in the radial direction by $61 \mathrm{~nm}$ on average (cyan bar). The distribution following these movements is comparable with the distribution in Fig. $2 \mathrm{~d}$ (purple bar). $\mathbf{h}$ The average relative position of the transcribing gene loci after induction. The distance in 3D geometry is presented. Data represent mean \pm s.d. obtained from three independent experiments (red). Each point represents independent measurement (black)

membrane (Fig. 2a and Supplementary Fig. 3). Thus, we analyzed the locations of the fluorescent foci in each cell over time after inducing transcription with IPTG (Fig. 2b-d). Typical twodimensional (2D) Gaussian fitting was used to determine the locations of fluorescent foci, which resulted in an $\sim 70$-nm localization resolution in our measurements (Supplementary Fig. 4a). Then, the normalized positions $(x, y)$ of the foci in the $2 \mathrm{D}$ projection relative to the short and long axes of each cell, respectively, were determined to account for size differences between cells (Fig. 2b). Although the localization error of each dot was 70 $\mathrm{nm}$, the error of the averaged subcellular localization was lower than $30 \mathrm{~nm}$, as the number of measured foci increased to 350 at the $5 \%$ significance level (Supplementary Fig. $4 \mathrm{~b}-\mathrm{d}$ ).

To determine whether the spatial localization of actively transcribing genes varies, we obtained the distributions of the relative positions of foci in the $\mathrm{x}$-axis within different time windows after transcription induction (Fig. 2b-d). Figure $2 \mathrm{c}$ shows the distribution of transcription foci appearing within $50 \mathrm{~s}$ 
after induction. This distribution is similar to the distribution of FP-labeled LacI (Supplementary Fig. 5), which denotes the locations of the lac operon without transcription (repressed condition $)^{31}$. Interestingly, transcription foci that appeared between 300 and $350 \mathrm{~s}$ after induction moved to the nucleoid periphery (radial movement), and their distribution was significantly different compared with their initial distribution (Fig. 2d). The difference in the average position on the relative $\mathrm{x}$-axis between the initial $(<50 \mathrm{~s})$ and final conditions (300-350 s) was 0.07 (normalized value), which corresponds to $61 \mathrm{~nm}$ in $3 \mathrm{D}$ geometry (Supplementary Note 2).

To test whether a movement of $61 \mathrm{~nm}$ to the nucleoid periphery induced the differences in transcription distribution that we observed, we performed a simulation (Fig. 2e-g); we randomly generated 100,000 spots with boundary conditions of $-l<x_{i}, y_{i}<l$ and a radial distance $\left(r=\sqrt{x_{i}^{2}+y_{i}^{2}}\right)<l$ to mimic nucleoid condensation and gave a 70-nm localization error for each spot (Fig. 2e). When $l$ equaled 0.35 , the simulated distribution in the $\mathrm{x}$-axis was very similar to that in Fig. $2 \mathrm{c}$, which shows the initial transcription distribution (Fig. 2f). Then, we randomly moved the spots in the radial direction by an average of $61 \mathrm{~nm}$ (Supplementary Note 2). The relocated distribution determined by the simulation matched well with the distribution shown in Fig. 2d (Fig. 2g). As shown in Fig. 2h, the average relative position of transcribing genes along the $\mathrm{x}$-axis increased steadily over time, which indicates that the gene locus moved to the nucleoid periphery due to active transcription by T7 RNAP. Our results imply that transcription is initiated within the nucleoid and then the gene locus being transcribed by T7 RNAP moves to the nucleoid periphery.

Because we placed tandem transcription terminator sites in the 4.5-kbp region, the $T 7 \mathrm{p} \_4.5 \mathrm{~kb}$ strain expresses both LacZ and LacY. Thus, it is possible that the transertion of LacY, i.e., the cotranscriptional translation and simultaneous insertion of membrane proteins in the plasma membrane ${ }^{42}$, causes repositioning of the chromosomal locus. To remove the effect of transertion on gene movement, we used the $T 7 \mathrm{p} \_3.3 \mathrm{~kb}$ strain, which contains only lacZ. Again, we observed the repositioning of the transcribed gene locus in the T7p_3.3kb strain (Supplementary Fig. 6), which was nearly identical to the results obtained in the T7p_4.5kb strain (Supplementary Fig. 7). This result indicates that the gene movement was not mainly caused by the expression of the membrane protein LacY in our observation time window.

Movement of a non-membrane protein gene loci by $E$. coli RNAP. Our observation that transcription by T7 RNAP causes the movement of gene loci immediately raises the question of whether this movement also occurs with transcription by endogenous E. coli RNAP. Endogenous E. coli RNAP transcribes $\sim 4000$ genes. Thus, it is impossible to identify the location of a specific gene by using fluorescence-labeled E. coli $\mathrm{RNAP}^{23}$. We used an alternative method of marking the location of a gene using DNA-binding proteins ${ }^{35,36}$. We incorporated six tandem TetO sites $(6 \mathrm{xTetO})$ downstream of the lacZ gene in an $E$. coli chromosome (strain lacZ-6xTetO) without the membrane protein lacY gene. The TetO-binding protein TetR fused with eYFP (TetR-eYFP) was expressed from an inducible plasmid (Fig. 3a). We detected diffraction-limited TetR-eYFP spots in cells with a localization error of $\sim 30 \mathrm{~nm}$, allowing localization of the lac $Z$ genes (Fig. 3a). The localized TetR-eYFP foci without the $6 x$ TetO site in the genome were not observed (Supplementary Fig. 8). Then, the relative positions of the TetR-eYFP foci were determined along the short axis (x-axis) of E. coli cells, as performed in Fig. 2. The time-dependent averaged locations of the fluorescent foci were plotted after transcription was induced with $1 \mathrm{mM}$
IPTG (Fig. 3b, c). The average locations of the foci moved to the nucleoid periphery (Fig. 3b, blue, Supplementary Movies 1 and 2). Then, we replaced lac $Z$ with the mCherry gene to check that the movement was not lac $Z$ gene-specific (Fig. 3c). The mCherry gene (which encodes a non-membrane protein) also moved to the nucleoid periphery by transcription of E. coli RNAP (Fig. 3c). Thus, movement of gene loci to the nucleoid periphery generally occurs by both T7 RNAP- and E. coli RNAP-driven transcription.

Effect of translation on gene locus movement. What factor is responsible for the observed movement of gene loci during transcription? The transertion of a membrane protein was not the major factor underlying this movement (Supplementary Fig. 7). Because ribosomes are typically excluded from the nucleoid ${ }^{43}$, the formation of a large DNA-RNAP-mRNA-ribosome complex may induce the movement of gene loci during transcription. To test this possibility, we blocked ribosome binding to mRNA and the coupling between transcription and translation by deleting the ribosomal binding site (RBS) from the lacZ gene (lacZ-6xTetO_ARBS) (Fig. 3b, d). We used E. coli RNAP-driven transcription in this study because transcription by $E$. coli RNAP is coupled with translation while T7 RNAP transcription is decoupled with translation. RBS-deleted strains expressed several hundred times lower levels of lacZ proteins than a control strain (Miller assays, Supplementary Fig. 9). Interestingly, relocation of the gene locus during transcription was dramatically reduced in the RBS-deleted strain (Fig. 3b, gray); the movement of the lac $Z$ gene locus with the RBS was $\sim 32 \pm 9 \mathrm{~nm}$, while nearly no movement was observed for the lac $Z$ gene locus without the RBS $(2 \pm 4 \mathrm{~nm})$ (Fig. $3 \mathrm{~d})$. When we inhibited translation initiation using kasugamycin (Ksg) treatment ${ }^{44}$, no movement of the gene locus after transcription induction was observed (Supplementary Fig. 10). This result is consistent with the results in the RBSdeletion strain (lacZ-6xTetO__RBS) (Fig. 3d). Then, we enhanced the gene expression level by increasing the temperature to $37^{\circ} \mathrm{C}$ (Fig. 3e). As the expression level increased, the distance moved by the gene locus with the RBS (lacZ-6xTetO) increased to $48 \pm 7 \mathrm{~nm}$ (Fig. 3e, blue bars). Again, when the RBS was deleted (lacZ-6xTetO_ $\triangle \mathrm{RBS}$ ), the distance moved by the gene locus was dramatically reduced to $18 \pm 11 \mathrm{~nm}$ (Fig. 3e, gray bar). Then, to completely abolish translation, we removed the start codon from the lac $Z$ mRNA (Fig. 4a) and found that the strain showed stronger translation inhibition than that in the RBS-deleted strain (Fig. 4b). As expected from the decreased translation activity, we did not observe gene movement in the strain, in which the start codon from the LacZ mRNA had been deleted, at $37^{\circ} \mathrm{C}$ (Fig. $4 \mathrm{c}$ ). The degree of gene movement was strongly correlated with translation activity (Fig. 4d). These results show that translation contributes to the subcellular relocation of gene loci under transcription in E. coli.

Gene loci movement depends on the transcriptional activity. Distinct foci, formed by E. coli RNAPs and located at the nucleoid periphery under rapid growth conditions, have been suggested to be highly transcribed genes $20,22,23$. It is still unclear whether the gene loci located at the nucleoid periphery are highly expressed by RNAP or whether the gene loci located inside the nucleoid move to the nucleoid periphery during transcription. In addition, it is unknown whether the distance of the movement of a specific gene locus to the nucleoid periphery depends on transcriptional activity $^{23}$. Our temperature-dependent measurements demonstrated that movement of the gene locus to the nucleoid periphery increases as transcriptional activity increases (Fig. 3d, e). To further support this observation, we constructed a strain that expressed LacZ more actively (Fig. 5a). The T7 RNAP 
a
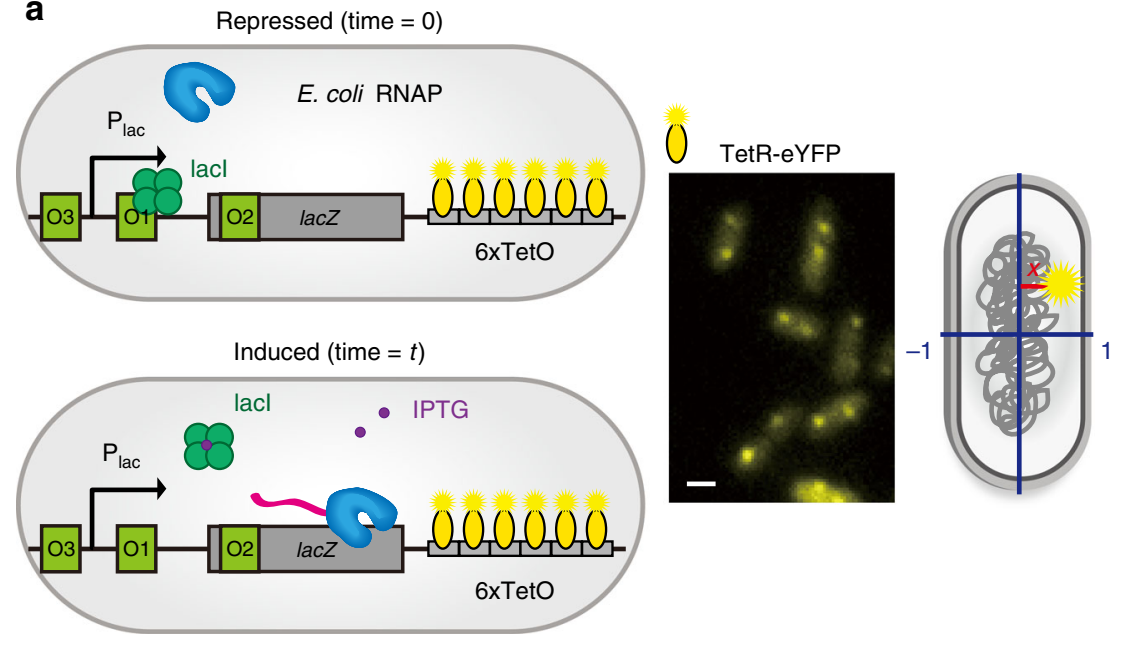

b

lacZ-6xTetO
lacZ-6xTetO_ARBS

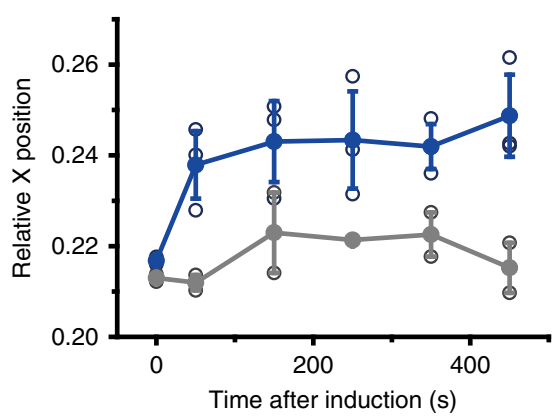

d

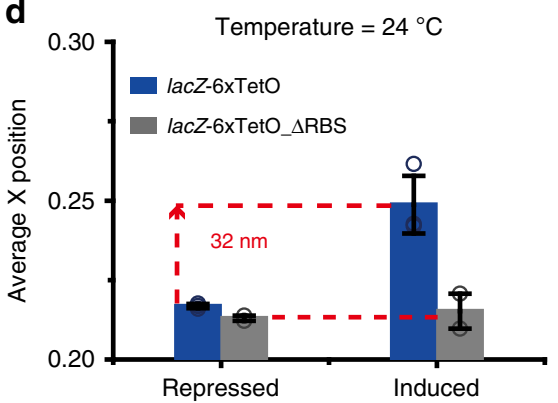

c

- mCherry-6xTetO $\stackrel{\mathrm{P}_{\mathrm{lac}}}{\longrightarrow} \mathrm{RBS}$ mCherry uwewey

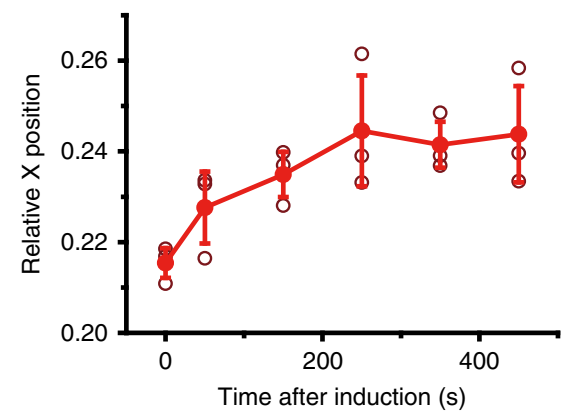

e

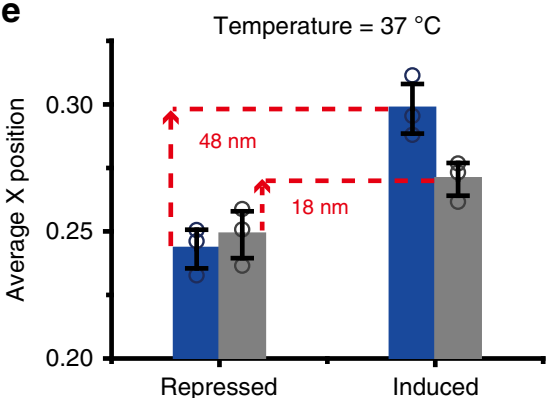

Fig. 3 Direct observation of the movement of a non-membrane protein gene locus by transcription of E. coli RNAP. a A schematic of the gene system used to detect location of the lacZ gene locus transcribed by E. coli RNAP (left panel). Six repeats of TetO (6xTetO) were inserted downstream of the lacZ gene or $m$ Cherry gene transcribed by E. coli RNAP. TetR-eYFPs bound to the TetO array were detected as a fluorescent spot (middle panel). The localization error was $30 \mathrm{~nm}$. Scale bar, $1 \mu \mathrm{m}$. b Quantitative analysis of the movement of the lacZ gene locus. The lacZ gene locus moved to the nucleoid periphery after IPTG induction (lacZ-6xTetO strain, blue squares) (>1500 spots). Movement of the lacZ gene locus following the RBS deletion (lacZ-6xTetO_ $\Delta$ RBS strain, gray circles) was not observed ( $>800$ spots). Data represent mean \pm s.d. obtained from three independent experiments. Each point represents independent measurement. c Quantitative analysis of $m$ Cherry gene locus movement. Movement of the $m C h e r r y$ gene to the nucleoid periphery was observed after IPTG induction ( $m$ Cherry-6xTetO, red squares) ( $>940$ spots). Data represent mean \pm s.d. obtained from three independent experiments. Each point represents independent measurement. d, e Comparison of gene locus movement with and without the RBS at $24^{\circ} \mathrm{C}$ (d) and $37^{\circ} \mathrm{C}(\mathbf{e})$. Average relative $x$-positions of gene loci were obtained without IPTG (repressed) and 5 min after adding IPTG (induced). Blue bar, lacZ-6xTetO, and gray bar, lacZ-6xTetO_ $\Delta$ RBS. Bar and error bars represent mean \pm s.d. from three independent experiments. Each point represents independent measurement

transcription system allows us to control the transcriptional activity through T7 RNAP concentration variation. Thus, we used T7 RNAP transcription system in this study. High transcription levels were achieved by using high concentrations of T7 RNAP, and the gene location was detected by $12 x$ TetO (T7p_lacZ$12 \mathrm{xTetO})$. Indeed, the distance moved by the lac $Z$ gene locus was significantly increased to $81 \pm 14 \mathrm{~nm}$ at $24^{\circ} \mathrm{C}$ (Fig. 5b-d) relative to the $32 \pm 9 \mathrm{~nm}$ distance driven by $E$. coli RNAP, as shown in Fig. $3 \mathrm{~d}$. In addition, the outward movement of the lac $Z$ gene locus in the axial direction $(78 \pm 32 \mathrm{~nm})$ was also observed in the T7p_lacZ-12xTetO strain (Supplementary Fig. 11), which was not observed in other experimental conditions that expressed less 
a

$\begin{array}{ll}\text { WT } & \text { CACAGGAAACAGCTATGACC } \\ \Delta \text { RBS } & \text { CACTCTCTCCAGCTATGACC } \\ \Delta \text { RBS } \triangle \text { ATG } & \text { CACTCTCTCCAGCTTAAACC }\end{array}$
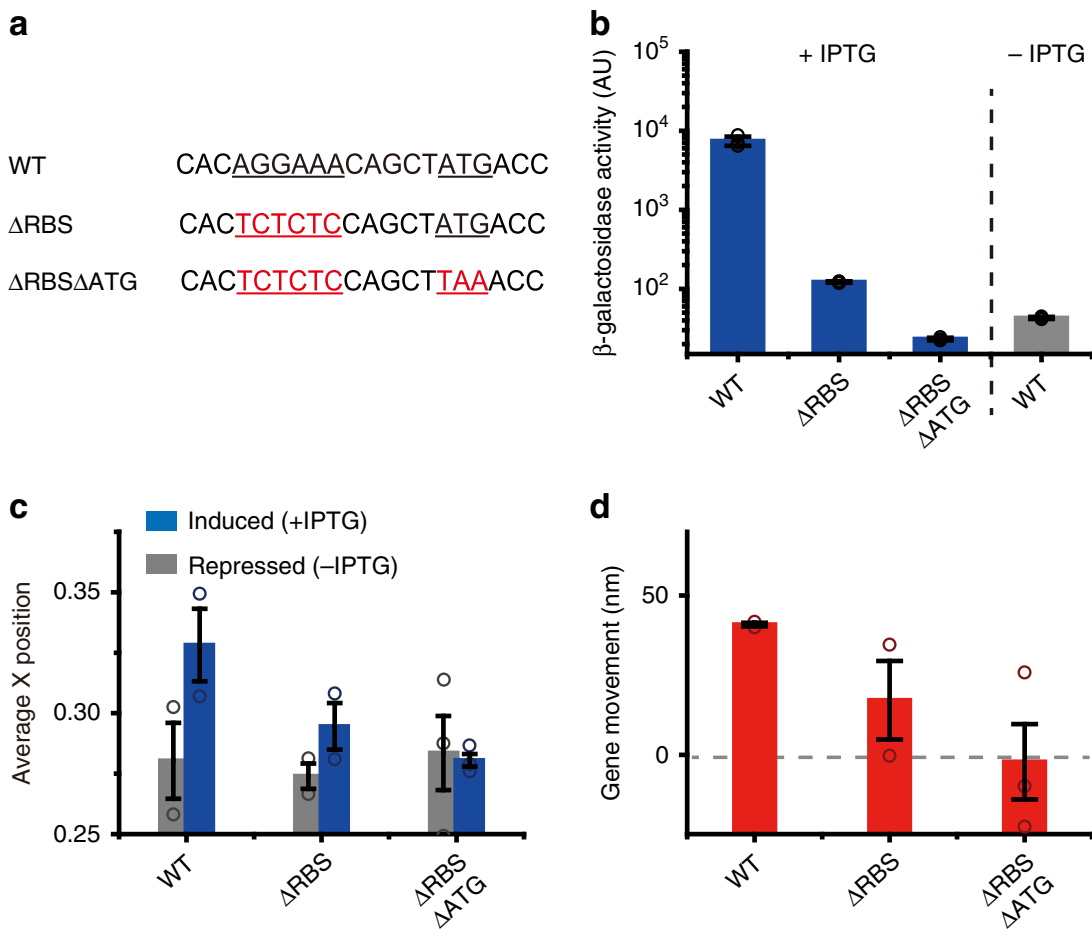

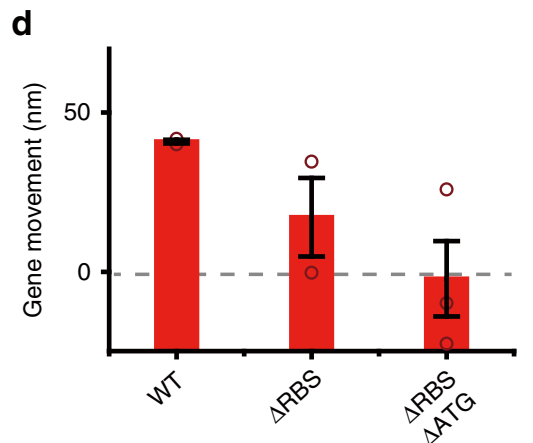

Fig. 4 Translation-dependent gene loci movement toward the nucleoid periphery in E. coli RNAP transcription. a $5^{\prime}$ UTR sequence of the mutated strains. The underlined AGGAAA in the WT strain (lacZ-12xTetO) was mutated to TCTCTC (red letters) ( $\triangle$ RBS, lacZ-12xTetO_ $\Delta$ RBS) for RBS substitution. The start codon of the lacZ gene (underlined) was mutated to TAA ( $\triangle$ RBS $\triangle$ ATG, lacZ-12xTetO_ $\Delta$ RBS_ $\Delta$ ATG). $\mathbf{b} \beta$-galactosidase assay showing that LacZ expression in the strain in which the start codon in the $\triangle$ RBS strain was replaced by a stop codon ( $\triangle$ RBS $\Delta$ ATG) decreased to $\sim 20 \%$ of that in the $\Delta$ RBS strain (blue bars, $1 \mathrm{mM}$ IPTG induction of each strain). The LacZ expression level in $\triangle$ RBS $\triangle$ ATG cells was lower than that in WT cells under repressed conditions (no IPTG, gray bar). c Average x-positions of the lac $Z$ gene locus were determined in the absence (repressed, gray bars) and presence of IPTG (induced, blue bars). d The degree of gene movement is the difference in the average position before (repressed) and after (induced) induction in $\mathbf{c}$. Bar and error bars represent mean \pm s.d. from three independent experiments. Each point represents independent measurement

amounts of mRNAs compared with T7p_lacZ-12xTetO strain. This result clearly shows that the transcription reaction induces the relocation of gene loci and that the degree of this movement depends on transcriptional activity.

Then, we measured the extent of gene locus movement relative to the size of the nucleoid. We imaged the nucleoid using SYTOX-Green dye $e^{45}$. The nucleoid width and length were defined as the full-width at half-maximum of the intensity profiles of SYTOX fluorescent images, as described by Bakshi et al. ${ }^{45}$. (Supplementary Fig. 12). The size of the nucleoids was maintained for the various measurements using both T7 RNAP and E. coli RNAP (short axis $=0.60 \pm 0.01 \mu \mathrm{m}$ ). Thus, the width of the nucleoid from the center of the cell was $300 \mathrm{~nm}$. As a result, gene movements during E. coli RNAP transcription $(30-50 \mathrm{~nm})$ and T7 RNAP transcription $(60-80 \mathrm{~nm})$ correspond to $10-16 \%$ and $20-27 \%$ of the nucleoid size (width), respectively.

Analysis of the factors contributing to gene loci movement. We showed that translation enhances gene locus movement in $E$. coli RNAP-driven transcription (Figs. $3 \mathrm{~d}$, e and 4). We then examined how translation influences gene locus movement. We first tested whether ribosome binding to mRNA, which results in the formation of a large DNA-RNAP-mRNA-ribosome complex, induces the relocation of gene loci. To remove the effects of direct interactions between RNAPs and ribosomes ${ }^{15-17}$ and quantify only the effect of ribosome binding to mRNAs to the degree of gene loci movement, we used T7 RNAP-driven transcription for this analysis (T7p_lacZ-12xTetO). T7 RNAP has no known interaction with ribosomes and moves approximately five times faster than E. coli RNAP. We blocked ribosome binding to the
DNA-T7RNAP-mRNA complex by adding Ksg, which inhibits translation initiation ${ }^{44}$. The blocking of translation initiation resulted in a reduced gene locus movement of $59 \pm 2 \mathrm{~nm}$ (Fig. 5e and Supplementary Fig. 13), which is $\sim 30 \%$ less than the movement observed without Ksg (Fig. 5d). Since it has been known that Ksg treatment leads to the change in the nucleoid morphology 44 , we assessed whether the nucleoid morphology before and after Ksg treatment differ and observed no change in the nucleoid morphology in our experimental conditions (Supplementary Fig. 14). To confirm this result without using antibiotics, we constructed RBS-deleted strains for T7 RNAP-driven transcription (Fig. 5f). The deletion of the RBS from the lac $Z$ gene (T7p_4.5kb $\Delta \mathrm{RBS}$ and T7p_3.3kb $\triangle \mathrm{RBS}$ ) also resulted in an $\sim 35 \%$ shorter gene locus movement in both strains (Fig. 5f). These results demonstrate that ribosomal translation of mRNA without transcription-translation coupling contributes to the subcellular relocation of genes undergoing transcription. As for T7 RNAPmediated transcription, transcriptional activity is the major factor driving gene locus movement. Considering that the spots we observed contain mostly single T7 RNAP (Fig. 1e), one DNA-T7RNAP-mRNA-ribosome complex seems to be required to drive movement of the transcribing gene locus toward the nucleoid periphery.

Although ribosome binding to mRNA increases movement by $30-35 \%$ in the T7 RNAP-driven system, this finding does not explain the effect of translation on the E. coli RNAP system in which movement increased significantly, as shown in Fig. 4. It has been reported that transcription activity of $E$. coli RNAP increases in the presence of the ribosomal protein $\mathrm{S} 1$ in vitro ${ }^{46}$. Thus, we suspected that transcription-translation coupling changes the 
a
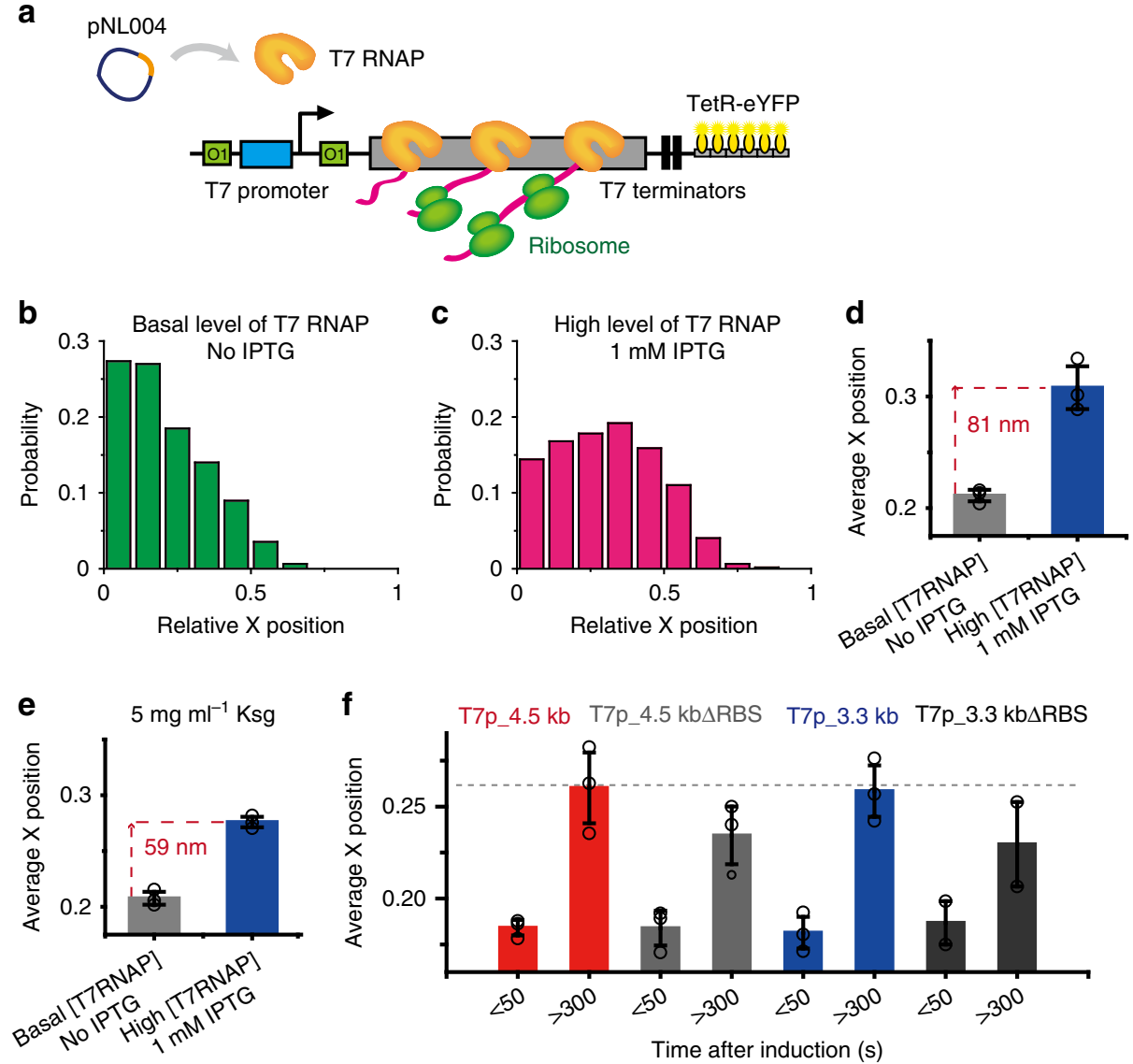

Fig. 5 Effects of transcriptional activity and ribosome binding to mRNA on gene locus movement. a Schematic of the gene system used to detect the location of the lacZ gene transcribed by wild-type T7 RNAP. Twelve repeats of TetO were inserted downstream of tandem T7 terminators. TetR-eYFP bound to the TetO array was detected as a fluorescent spot. T7 RNAP was expressed from an L-rhamnose inducible plasmid (pNL004). b, c Distributions of the subcellular localization of a gene locus transcribed by T7 RNAP. $\mathbf{b}$ The distribution of the gene locus with a basal level of T7 RNAP (no rhamnose) and no IPTG. c The distribution of the gene locus when T7 RNAP was expressed by the addition of $0.2 \%$ L-rhamnose and $1 \mathrm{mM} \mathrm{IPTG.} \mathbf{d}$ Comparison of gene locus movement. Average relative x-positions of the gene loci from Fig. 5b (gray bar, basal level of T7 RNAP and no IPTG) and Fig. 5c (blue bar, high expression of T7 RNAP and $1 \mathrm{mM}$ IPTG). e Comparison of gene locus movement under translation initiation inhibition conditions. The same experiment was performed as shown in Fig. $5 \mathrm{~d}$ after a 15 -min incubation with $5 \mathrm{mg} \mathrm{mL}^{-1}$ kasugamycin (Ksg), which inhibits translation initiation. $\mathbf{f}$ Comparison of gene loci movement with and without the RBS. Red and blue bars denote the average relative $x$-positions of lacZ gene loci of T7p_4.5 kb and T7p_3.3 kb, respectively, within each time window. When the RBS was deleted, gene locus movement was reduced by $\sim 30 \%$ (gray bars: T7p_4.5kb $\Delta$ RBS and dark gray bars: T7p_3.3kb $\Delta$ RBS). Bar and error bars represent mean \pm s.d. from three independent experiments. Each point represents independent measurement

gene expression level in E. coli RNAP transcription. We measured the mRNA expression level of $E$. coli RNAP-driven strains using RT-PCR (Supplementary Fig. 15). Indeed, LacZ mRNA with the RBS was expressed at a 36 -fold higher level relative to LacZ mRNA expression in the RBS-deleted strain (Supplementary Fig. 15a). Typically, the RBS deletion increases the mRNA degradation rate, which results in less mRNA at the steady state ${ }^{47}$. To take into account the rapid degradation of RBS-deleted mRNA, we measured the degradation rates of LacZ mRNA with and without the RBS. The half-life of LacZ mRNA was $5.5 \pm 0.8 \mathrm{~min}$, which was reduced to $2.4 \pm 0.3 \mathrm{~min}$ for the RBS-deleted strain (Supplementary Fig. 15b). Even after considering the short halflife of mRNA, the expression level of mRNA with the RBS was 16-fold higher than that without the RBS. To confirm the RTPCR results, we used fluorescence in situ hybridization (FISH) to measure mRNA levels (Supplementary Fig. 15c). Again, 24fold more mRNA was expressed with the RBS. Thus, transcription-translation coupling increased transcriptional activity relative to the decoupled case (without the RBS). The enhanced transcriptional activity with transcription-translation coupling may have increased gene locus movement.

\section{Discussion}

In this work, we have demonstrated that a gene locus moves to the nucleoid periphery by transcription. Gene locus movement depends on transcriptional activity, and translation coupled with transcription contributes significantly to gene locus movement in E. coli RNAP-driven transcription. Gene locus movement was observed in both T7 RNAP- and E. coli RNAP-dependent transcription, i.e., a common phenomenon of transcription in E. coli (see Supplementary Fig. 16 for a summary of the strains used in this work).

Transcription initiation via the binding of RNAP to a promoter occurs in the nucleoid region. A recent single-particle tracking experiment with ribosomes demonstrated that free ribosomal subunits are not excluded from the E. coli nucleoid ${ }^{48}$. This observation suggests that translation of nascent mRNA could start at any location in the nucleoid. Based on our results, we suggest that relocation of the gene locus by transcription occurs as follows (Fig. 6). The RNAP-promoter complex forms inside the nucleoid. Transcription induces relocation of the gene locus depending on transcriptional activity. As the ribosome binding sites of mRNAs are generated, free ribosomal subunits 


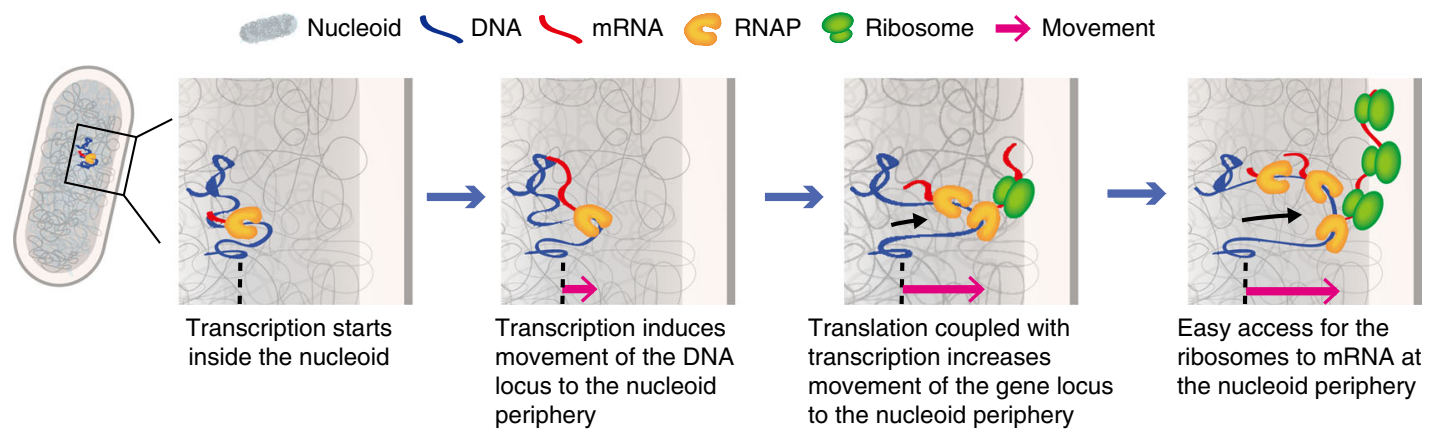

Fig. 6 Model of gene locus movement by transcription in E. coli cells. Transcription starts inside the nucleoid with formation of the RNAP-promoter complex. As soon as the ribosome binding site of mRNA is generated, free ribosomal subunits in the nucleoid region bind the mRNA. The DNA-RNAP-mRNA-ribosome complex moves further outside the nucleoid for easy ribosome access

present in the nucleoid region bind the mRNAs. The DNA-RNAP-mRNA-ribosome complex moves further outside the nucleoid due to the increased transcriptional activity and ribosome binding.

Our work shows that the major factor that causes the gene loci movement during transcription is different for T7 RNAP- and E. coli RNAP-driven transcription. As for E. coli RNAP-driven transcription, translation coupled with transcription causes most gene loci movement that the deletion of both RBS site and a start codon (decoupling between transcription and translation) nearly abolishes the gene loci movement (Figs. 3 and 4). However, the transcription by T7 RNAP is not coupled with translation. The deletion of RBS site causes only $30 \%$ less movement of gene loci (Fig. 5f), which means that ribosome binding to mRNA increases the gene loci movement only $30 \%$ more. Thus, as for T7 RNAPdriven transcription, the transcriptional activity causes most gene loci movement.

Jin et al. observed foci of transcribing RNAP located at the surface of the nucleoid under fast growth conditions ${ }^{20,29}$. These foci were suggested to be the locations of actively transcribing genes, such as rrn operons. Since ribosomal RNAs of rrn operons are not translated by ribosomes, RNAP foci under fast growth conditions may occur due to high transcriptional activity without transcription-translation coupling. A recent live-cell super-resolution imaging study showed that highly transcribing RNAPs tend to cluster at the edge of the nucleoid in minimal media growth conditions ${ }^{23}$. In this case, the gene locus may have moved to the nucleoid periphery mainly by transcription-translation coupling with forming a large DNA-RNAP-mRNA-ribosome complex.

How, then, is transcriptional activity correlated with the distance of gene locus movement? The entropic force and excluded volume effect are possible sources for the movement, which have been suggested to exclude ribosomes from the nucleoid ${ }^{43}$. In this model, DNA polymers are confined in the center of the cell by conformational entropy, while multiple 70S-polysomes formed on nascent mRNA inside the nucleoid diffuse outside the nucleoid due to the excluded volume effect. The large DNA-RNAP-mRNA-ribosome complex may feel a strong entropic force that would drive its movement outside the nucleoid. The other possible source is that high transcriptional activity may change the local environment of the gene locus, like DNA supercoiling 49,50 and the chromosomal loop structure formed by nucleoid-associated proteins (NAPs) ${ }^{51,52}$. It is well known that transcription accumulates positive supercoiling ahead of RNAP and negative supercoiling behind RNAP ${ }^{53}$. Supercoiling due to high RNAP activity would accumulate very rapidly before timely correction by topoisomerases and gyrase, which may change the local DNA structure size range from tens of nanometers to hundreds of nanometers ${ }^{54,55}$. In addition, DNA supercoiling is highly dynamic that can move by diffusion and hopping process ${ }^{56}$, affecting several kilobases away from the origin of the supercoiling ${ }^{57}$. Alternatively, high RNAP activity would dissociate NAPs from DNA, maintaining the bacterial chromosomal structure, which may also change the looping and local DNA structure.

\section{Methods}

Strains and plasmids. For the experiments with eYFP-T7 RNAP, Cat (chloramphenicol resistance gene)-O1-T7 promoter-O1 with or without lacZ RBS fragment was inserted into the lac promoter region of BW25993 using lambda red recombination to replace the lac promoter with the T7 promoter. T7p_4.5kb and $\mathrm{T} 7 \mathrm{p} \_4.5 \mathrm{~kb} \Delta \mathrm{RBS}$ strains were constructed by inserting tandem $\mathrm{T} 7$ terminators (Tpi)-kanamycin resistance gene (KanR) fragment into the downstream of lacY gene, resulting in $4.5 \mathrm{~kb}$ distance between the T7 promoter and T7 termination site. For the construction of T7p_3.3kb and T7p_3.3kb $\Delta R B S$ strains, we put a Tpi-KanR fragment downstream of the lac $Z$ gene. For the construction of the T7p_lacZ12xTetO strain, a KanR-12xTetO fragment was inserted into the downstream of T7 terminators in the strain T7p_3.3kb. The lacZ-6xTetO strain was constructed by inserting a KanR-6xTetO fragment downstream of the lac $Z$ gene, while lac $Y$ and $l a c A$ genes were deleted. The $m$ Cherry-6xTetO strain was constructed by replacing the lac $Z$ gene with the mCherry gene using lambda red recombination and then a KanR-6xTetO fragment was inserted into the downstream of the mCherry gene. The antibiotic genes were removed using a FRT cassette after successful cloning. NL003 strain was constructed by inserting a Tsr-eYFP gene with Cat into the lac operon for replacing the native lacZYA gene. All strains are described in Supplementary Fig. 16.

T7 RNAP fused with eYFP was expressed from a low-copy-number plasmid backbone pVS133 (pNL003). L-rhamnose was used to induce eYFP-T7 RNAP expression from the plasmid, which carries the ampicillin resistant gene (ampR) for antibiotic selection.

T7 RNAP expressed from a low-copy-number plasmid backbone pVS133 (pNL004). L-rhamnose was used to induce T7 RNAP expression from the plasmid, which carries chloramphenicol resistance gene for antibiotic selection.

Cell growth conditions. All strains were grown overnight in $\mathrm{LB}$ medium at $37^{\circ} \mathrm{C}$ from a single colony for eYFP-T7 RNAP experiments. The overnight cultures were re-inoculated into fresh M9 medium supplemented with $0.4 \%$ glycerol, amino acids, and vitamins at 1:100 dilution. The cells were grown for $4.5 \mathrm{~h}$ with $0.2 \% \mathrm{~L}$ rhamnose to induce eYFP-T7 RNAP expression $\left(\mathrm{OD}_{600} \sim 0.2\right)$. Then, the cells were pelleted by centrifugation for $1 \mathrm{~min}$ and re-suspended in a pre-warmed M9 medium supplemented with $0.4 \%$ glucose, amino acids, and vitamins at 1:3 dilution and grown for additional $2 \mathrm{~h}$ without L-rhamnose (cell doubling time $\sim 55 \mathrm{~min}$ ). The change of the medium and the additional growth period without the expression of eYFP-T7 RNAP allows the maturation of the FPs already expressed in cells and the dilution of eYFP-T7 RNAP to a proper concentration in a cell for the single-protein detection. For $6 \mathrm{xTetO}$ array measurements, cells were grown at $30{ }^{\circ} \mathrm{C}$ in a M9 medium supplemented with $0.4 \%$ glucose, amino acids, and vitamins to reach $\mathrm{OD}_{600} \sim 0.3$. After centrifugation, cells were resuspended to $\mathrm{OD}_{600} \sim 0.1$ with $0.4 \%$ glycerol, amino acids, vitamins, and $0.2 \% \mathrm{~L}$-arabinose and grown for $3 \mathrm{~h}$ to express TetR-eYFP. Then, cells were again pelleted by centrifugation and resuspended to $\mathrm{OD}_{600} \sim 0.1$ with $0.4 \%$ glucose, amino acids, and vitamins and grown for another $3 \mathrm{~h}$ (cell doubling time $\sim 99 \mathrm{~min}$ ). This procedure was required for the maturation of FPs and proper dilution of TetR-eYFP for single-protein imaging. For T7p_lacZ-12xTetO experiments, cells were grown overnight in LB medium at $37^{\circ} \mathrm{C}$ from a single colony. The overnight cultures were re-inoculated 
into a fresh M9 medium supplemented with $0.4 \%$ glycerol, amino acids, and vitamins at 1:100 dilution. The cells were grown for $4.5 \mathrm{~h}$ with $0.2 \% \mathrm{~L}$-rhamnose to induce T7 RNAP expression and $0.2 \% \mathrm{~L}$-arabinose to induce TetR-eYFP expression $\left(\mathrm{OD}_{600} \sim 0.2\right)$. Then, the cells were pelleted by centrifugation for $1 \mathrm{~min}$ and resuspended in a pre-warmed M9 medium supplemented with $0.4 \%$ glucose, amino acids, and vitamins at 1:3 dilution and grown for additional $2 \mathrm{~h}$ without $\mathrm{L}$-arabinose. This additional growth period without the expression of TetR-eYFP allows the maturation of the FPs already expressed in cells and the dilution of TetR-eYFP to a proper concentration in a cell for the TetO array detection.

Fluorescence microscope and image acquisition. Cells were pelleted by centrifugation for $1 \mathrm{~min}$ and resuspended with a fresh $\mathrm{M} 9$ medium supplemented with $0.4 \%$ glucose for washing, then pelleted again by centrifugation and resuspended with a fresh M9 medium supplemented with $0.4 \%$ glucose in a final volume of $40 \mu \mathrm{L}$. Then, $15 \mu \mathrm{L}$ of the cells was dropped in the center of glass bottom dish (MatTek, P35G-1.0-14-C) coated with a poly-L-lysine (Sigma, P8920) for immobilizing the cells at the surface of the glass, which were incubated for $10 \mathrm{~min}$ at room temperature. After removing the non-immobilized cells from the glass surface, $2 \mathrm{~mL}$ of a fresh M9 medium supplemented with $0.4 \%$ glucose was applied to the glass bottom dish. Samples were imaged on an inverted microscope (Olympus, IX-71) with a $100 \times$ oil-immersed objective lens (Olympus) and additional 1.6x amplification. In order to induce transcription, $1 \mathrm{~mL}$ of a M9 medium supplemented with $0.4 \%$ glucose containing $3 \mathrm{mM}$ IPTG was added to the $2 \mathrm{~mL}$ of the medium in the glass bottom dish to make the final concentration of $1 \mathrm{mM}$ IPTG. Phase contrast images and eYFP fluorescence images were acquired at different positions at every $10 \mathrm{~s}$ using a cooled EMCCD camera (Andor iXon DU897) equipped with a dichroic mirror (FF520-Di01-25x36, Semrock), an excitation filter (FF03-510/20, Semrock), and an emission filter (HQ550/50m, Chroma). Excitation was provided by an Ar-ion laser (Melles Griot 43 Series Ion Laser) at $514 \mathrm{~nm}$ with an intensity of $\sim 0.3 \mathrm{~kW} \mathrm{~cm}^{-2}$. Metamorph software (Molecular Devices) was used to control the automated measurements. All experiments were carried out at room temperature $\left(24^{\circ} \mathrm{C}\right.$ ) (cell doubling time $\sim 220 \mathrm{~min}$ ), unless otherwise specified.

As for the measurements using $6 \mathrm{xTetO}$ array at $37^{\circ} \mathrm{C}$ (cell doubling time $\sim 55 \mathrm{~min}$ ), 1-mL aliquot of cells was pelleted by centrifugation and resuspended with a fresh M9 medium to be a final volume of $15 \mu \mathrm{L}$, and then $1 \mu \mathrm{L}$ of the cells was placed between a coverslip and a 1.5\% low-melting-temperature agarose gel pad (Lonza, \#50111) prepared with a M9 medium. The sample chamber was attached to a temperature controller (FCS2, Bioptechs) and maintained at $37^{\circ} \mathrm{C}$ during the experiments. To provide a continuous flow of fresh medium, prewarmed M9 medium supplemented with $0.4 \%$ glucose, amino acids, and vitamins was supplied by a syringe pump at $0.3 \mathrm{~mL} \mathrm{~min}^{-1}$ rate. For transcription induction, $10 \mathrm{mM}$ IPTG was added to a flow of a M9 medium supplemented with $0.4 \%$ glucose, amino acids, and vitamins and images were acquired after $20 \mathrm{~min}$ of IPTG treatment.

For Ksg-treatment experiments, cells were prepared on the glass-bottom dishes. Then, cells were incubated in $2 \mathrm{~mL}$ of fresh M9 medium supplemented with $0.4 \%$ glucose and $5 \mathrm{mg} \mathrm{mL}^{-1} \mathrm{Ksg}$ (Sigma-Aldrich, \#32354). To induce transcription, $1 \mathrm{~mL}$ of a M9 medium supplemented with $0.4 \%$ glucose containing $3 \mathrm{mM}$ IPTG and $15 \mathrm{mg} \mathrm{mL}^{-1} \mathrm{Ksg}$ was added to the $2 \mathrm{~mL}$ of the medium in the glass bottom dish to make the final concentration of $1 \mathrm{mM}$ IPTG and $5 \mathrm{mg} \mathrm{mL}^{-1} \mathrm{Ksg}$.

Analysis of fluorescence images. The images were analyzed using home-built software (Matlab). The program identified the boundaries of individual cells from the phase-contrast images and calculated the total fluorescence intensity of each cell from the fluorescence images automatically. The intensity of auto-fluorescence was obtained from the cells without the plasmid pNL003, which expresses eYFP-T7 RNAP. In the analysis, we excluded cells having too many eYFP-T7 RNAPs, because it is difficult to determine the specific binding above the high fluorescence background. The program found automatically the region where the integrated fluorescence level of $5 \times 5$ pixels is the maximum in a cell (denoted as ROMIF, Region of Maximum Integrated fluorescence level). The cellular background level of each cell was determined by the average of the fluorescence intensity of whole cellular region except for the ROMIF. Then, the fluorescence intensity of eYFPT7RNAP, denoted as $\overline{I_{\max }}$ where the over-bar denotes the mean over the $5 \times 5$ area, was calculated by following:

$$
\overline{I_{\max }}=\overline{\text { Intensity of the ROMIF }}-\overline{\text { cellular background }} .
$$

Then, $\overline{I_{\max }}$ of each cell was averaged over all cells at the specific time $t, \overline{\left\langle I_{\max }(t)\right\rangle}$. Average over a cell population is indicated by the angled brackets.

The average fluorescence intensity from the transcribing eYFP-T7 RNAPs bound to DNA was obtained from:

$$
I_{\text {transcribing }}(t)=\overline{\left\langle I_{\max }(t)\right\rangle}-\overline{\left\langle I_{\max }(0)\right\rangle},
$$

where $\overline{\left\langle I_{\max }(0)\right\rangle}$ is the average of $I_{\max }$ obtained from the repressed condition, i.e., without IPTG induction (defined as time $=0$ ).

Finally, the average number of transcribing T7 RNAPs was calculated by dividing the $I_{\text {transcribing }}(t)$ by the single eYFP intensity $\overline{\left\langle I_{\text {single }}\right\rangle}$, obtained in
Supplementary Fig. 1. Detailed process of how $\overline{\left\langle I_{\text {single }}\right\rangle}$ was obtained is described in the next section.

Quantification of fluorescence intensity of a single eYFP. We constructed a strain expressing membrane-bound Tsr-eYFP (NL003) ${ }^{32}$ and quantified the fluorescence intensity of single eYFPs under the same imaging condition as the eYFP-T7 RNAP measurements (Supplementary Fig. 1). Fluorescence intensity from single eYFPs was obtained by measuring the integrated intensity of the fluorescence dot in $5 \times 5$ pixels (Supplementary Fig. 1a, b). The distribution of the integrated fluorescence intensity (denoted as $\left.\left\langle I_{\text {single }}\right\rangle\right)$ from each eYFP is shown in Supplementary Fig. 1c. We used $\left\langle\overline{I_{\text {single }}}\right\rangle$, i.e., $\left\langle I_{\text {single }}\right\rangle / 25$, for calculating the average number of transcribing T7 RNAP in Fig. 1e. The average number of transcribing T7 RNAP (denoted as $\left.\left\langle\operatorname{RNAP}_{\text {transcribing }}\right\rangle\right)$ was obtained by $\frac{I_{\text {transcrbing }}(t)}{\left\langle\bar{I}_{\text {single }}\right\rangle}$.

Localization of diffraction-limited spots in a living cell. The location of the diffraction limited dot was determined by a least-squares fit of a 2D Gaussian point spread function to each spot (Supplementary Fig. 4a). The cellular areas identified from the phase-contrast images were fitted with a $2 \mathrm{D}$ elliptical function to determine the center, the short, and the long axes of the cells automatically. Two perpendicular lines relative to the cellular centroid were chosen as $x, y$ coordinates of each cell (Fig. 2b). Then, the normalized relative position of each dot was determined. We mapped the positions of all foci into the first quadrant of the cell based on the cylindrical symmetry of E. coli cell.

Measuring in vivo elongation rate of RNAP. A total of $643 \mu \mathrm{L}$ of cells in a fresh M9 medium was prepared; $43 \mu \mathrm{L}$ of cells were withdrawn into $150 \mu \mathrm{L}$ of pre-cooled RNAlater solution (Ambion, AM7020) before adding IPTG (this is the sample for $0 \mathrm{~s})$. Then, $100 \mu \mathrm{L}$ of $7 \mathrm{mM}$ IPTG in a M9 medium was added into the remaining $600 \mu \mathrm{L}$ of cells and $50 \mu \mathrm{L}$ of cells was withdrawn into $150 \mu \mathrm{L}$ of pre-cooled RNAlater solution at each time point, typically every $10 \mathrm{~s}$. After sampling, cells were cooled on ice for $20 \mathrm{~min}$. A total of $400 \mu \mathrm{L}$ of pre-cooled M9 medium was added to cells and gently mixed by pipetting $(407 \mu \mathrm{L}$ of $\mathrm{M} 9$ medium was added into $0 \mathrm{~s}$ sample). Cells were collected by centrifugation at $10,000 \mathrm{rpm}, 4^{\circ} \mathrm{C}$ for $2 \mathrm{~min}$. Supernatant was discarded carefully and then the pellets were re-suspended in $100 \mu \mathrm{L}$ of pre-cooled lysozyme solution ( $10 \mathrm{mM}$ Tris- $\mathrm{HCl} \mathrm{pH} \mathrm{8.0,0.1} \mathrm{mM} \mathrm{EDTA,}$ $10 \mathrm{mg} \mathrm{mL}^{-1}$ lysozyme (Sigma, L4919)) and vigorously vortexed for $20 \mathrm{~s}$ to break cell walls. Then, $0.5 \mu \mathrm{L}$ of $10 \%$ SDS solution (Sigma, L3771) dissolved in $1 \mathrm{~mL}$ of RNase-free water (PureLink RNA Mini Kit, Invitrogen, 12183018 A) was added to cells and vortexed for $10 \mathrm{~s}$. Cells were incubated at room temperature for $5 \mathrm{~min}$. $350 \mu \mathrm{L}$ of lysis buffer (PureLink RNA Mini Kit) containing 1\% beta-

mercaptoethanol (Sigma, M3148) was added to cells and vortexed for $10 \mathrm{~s}$. Then, total RNA was extracted following the procedures described in the quick reference of PureLink RNA Mini Kit. Using the extracted total RNA, we performed real-time RT-PCR. First-strand cDNAs were synthesized using Superscript III Reverse Transcriptase (Invitrogen, 18180-044) and RNaseOut Recombinant Ribonuclease Inhibitor (Invitrogen, 10777-019). The following reaction mixture was incubated at $50{ }^{\circ} \mathrm{C}$ for $60 \mathrm{~min}$, and heat inactivated at $70^{\circ} \mathrm{C}$ for $15 \mathrm{~min}: 3 \mu \mathrm{L}$ of RNase-free water, $2 \mu \mathrm{L}$ of total RNA, $2 \mu \mathrm{L}$ of $5 \times$ first-strand buffer, $1 \mu \mathrm{L}$ of $100 \mu \mathrm{M}$ reverse primers ( $\mathrm{N}$ rev or $\mathrm{C}$ rev), $0.5 \mu \mathrm{L}$ of dNTP (invitrogen, 18427-013), $0.5 \mu \mathrm{L}$ of $0.1 \mathrm{M}$ DTT, $0.5 \mu \mathrm{L}$ of RNaseOut Recombinant RNase Inhibitor $\left(40 \mathrm{U} \mu \mathrm{L}^{-1}\right)$, and $0.5 \mu \mathrm{L}$ of superscript III reverse transcriptase $\left(200 \mathrm{U}_{\mu} \mathrm{L}^{-1}\right)$. cDNAs were temporally stored at $4{ }^{\circ} \mathrm{C}$ for the next step. For quantitative polymerase chain reaction (qPCR), cDNAs were amplified using TaqMan Universal Master Mix II with UNG (Applied Biosystems, 4440038) and Custom TaqMan Gene Expression Assays (Applied Biosystems) on StepOne Real-Time PCR System (Applied Biosystems, 4376357) with the following reaction mixture condition: $3.5 \mu \mathrm{L}$ of RT-PCR Grade Water (Ambion, AM9935), $5 \mu \mathrm{L}$ of TaqMan Universal Master Mix II with UNG, $0.5 \mu \mathrm{L}$ of Custom TaqMan Gene Expression Assays, and $1 \mu \mathrm{L}$ of cDNA. The run method contained a holding stage with initial heating at $50^{\circ} \mathrm{C}$ for $2 \mathrm{~min}$ and an initial denaturation step at $95^{\circ} \mathrm{C}$ for $10 \mathrm{~min}$, followed by a cycling stage for 40 cycles with a denaturation step at $95^{\circ} \mathrm{C}$ for $15 \mathrm{~s}$ and an annealing/amplification step at $60^{\circ} \mathrm{C}$ for $1 \mathrm{~min}$. The sequences of the primers and probes used for real-time RT-PCR measurement are summarized in Supplementary Table 1.

mRNA degradation rate measurement. E. coli strain BW25993 and lacZ $\triangle$ RBS (without RBS for lacZ gene of BW25993) strains were grown to mid-log phase and cooled to $4{ }^{\circ} \mathrm{C}$ for $1 \mathrm{~h}$. Cells were concentrated $\left(\mathrm{OD}_{600} \times\right.$ volume $\left.\sim 0.8\right)$ with $24^{\circ} \mathrm{C}$ M9 medium (supplemented with $0.4 \%$ glucose, amino acids, and vitamins), then $1 \mathrm{mM}$ IPTG was added for $30 \mathrm{~min}$ to express lac $Z$ mRNA. At time zero, rifampicin was added to the final concentration of $300 \mathrm{ng} \mu \mathrm{L}^{-1}$. Six samples were withdrawn with 2-min interval $(0,2,4,6,8,10 \mathrm{~min})$ to pre-cooled RNAlater solution. Total RNA purification, first strand CDNA synthesis, qPCR analysis (probe 1 was used to determine the abundance of lac $Z$ mRNA) were performed same as previously described. The result is plotted on a log scale to determine the half-life of lac $Z$ mRNA in our experimental conditions (Supplementary Fig. 15b).

$\boldsymbol{\beta}$-galactosidase assay. Overnight culture of cells was diluted 1:100 into M9 glycerol medium containing $1 \mathrm{mM}$ IPTG and $0.2 \%$ L-rhamnose (SIGMA, R3875). 
The culture was grown for $6 \mathrm{~h}$ at $37^{\circ} \mathrm{C}$. Miller assays are conducted using the yeast $\beta$ galactosidase assay kit (Pierce, 75768). A total of $190 \mu \mathrm{L}$ of Y-PER reagent was added into $10 \mu \mathrm{L}$ of cells (cells were diluted or concentrated) and incubated at room temperature for $20 \mathrm{~min}$. Then, $190 \mu \mathrm{L}$ of $\mathrm{M} 9$ glycerol medium and $100 \mu \mathrm{L}$ of $2 \times$ assay buffer were added and incubated at $37^{\circ} \mathrm{C}$. The reaction was stopped with $171 \mu \mathrm{L}$ of stop solution. Cellular debris was removed by centrifugation for $5 \mathrm{~min}$ at $10,000 \times g$ and $500 \mu \mathrm{L}$ of supernatant was collected. $\beta$-galactosidase activity was determined using the following formula: $\left(1000 \times \mathrm{OD}_{420}\right) /\left(t \times \mathrm{V} \times \mathrm{OD}_{660}\right)$, where $t$ is the reaction time in minutes, and $V$ is the volume of cells used in the assay, milliliters.

Single-molecule fluorescence in situ hybridization (smFISH). We followed the protocol previously reported ${ }^{58}$. A total of 50 oligonucleotides labeled with Atto 594 were hybridized to the target lacZ mRNA. Cell cultures were fixed and permeabilized using $70 \%$ ethanol. Cells were then hybridized with the probe set, washed, and imaged using epifluorescence microscopy. Overnight culture of cells was diluted 1:200 into a M9 glucose medium supplemented with amino acids and vitamins. The cells were grown for $5 \mathrm{~h}$ with $1 \mathrm{mM}$ IPTG to induce lacZ expression $\left(\mathrm{OD}_{600} \sim 0.3\right)$. For imaging, excitation was provided by a fiber laser at $580 \mathrm{~nm}$ (VFL-P-Series, MPB Communications Inc.). Phase contrast images and fluorescence images for Atto 594 were acquired at multiple positions using a cooled EMCCD camera (Andor iXon DU897). A home-built software (Matlab) was used for image analysis. Phase contrast images were used to identify the cell area and shape. We used Spatzcells ${ }^{58}$ in the mRNA fluorescence images to quantify the lac $Z$ mRNA in individual cells.

Reporting Summary. Further information on research design is available in the Nature Research Reporting Summary linked to this article.

\section{Data availability}

The source data underlying Figs. $1 \mathrm{e}, 2 \mathrm{c}, \mathrm{d}, \mathrm{h}, 3 \mathrm{~b}-\mathrm{e}, 4 \mathrm{~b}-\mathrm{d}$, and $5 \mathrm{~b}-\mathrm{f}$ and Supplementary Figs. 1, 2, 5-7, and 9-15 are provided as a Source Data file.

\section{Code availability}

The analysis codes that were used in this study are available from the corresponding author upon request.

Received: 12 February 2019; Accepted: 21 October 2019;

Published online: 12 November 2019

\section{References}

1. Steitz, T. A. The structural changes of T7 RNA polymerase from transcription initiation to elongation. Curr. Opin. Struct. Biol. 19, 683-690 (2009).

2. Zhang, Y. et al. Structural basis of transcription initiation. Science 338 1076-1080 (2012).

3. Dutta, D., Shatalin, K., Epshtein, V., Gottesman, M. E. \& Nudler, E. Linking RNA polymerase backtracking to genome instability in E. coli. Cell 146, 533-543 (2011).

4. Abbondanzieri, E. A., Greenleaf, W. J., Shaevitz, J. W., Landick, R. \& Block, S. M. Direct observation of base-pair stepping by RNA polymerase. Nature 438, 460-465 (2005).

5. Bai, L., Santangelo, T. J. \& Wang, M. D. Single-molecule analysis of RNA polymerase transcription. Annu. Rev. Biophys. Biomol. Struct. 35, 343-360 (2006).

6. Kapanidis, A. N. et al. Initial transcription by RNA polymerase proceeds through a DNA-scrunching mechanism. Science 314, 1144-1147 (2006).

7. Tang, G. Q., Roy, R., Bandwar, R. P., Ha, T. \& Patel, S. S. Real-time observation of the transition from transcription initiation to elongation of the RNA polymerase. Proc. Natl Acad. Sci. USA 106, 22175-22180 (2009).

8. Wang, F. \& Greene, E. C. Single-molecule studies of transcription: from one RNA polymerase at a time to the gene expression profile of a cell. J. Mol. Biol. 412, 814-831 (2011).

9. Michaelis, J. \& Treutlein, B. Single-molecule studies of RNA polymerases. Chem. Rev. 113, 8377-8399 (2013).

10. Koh, H. R. et al. Correlating transcription initiation and conformational changes by a single-subunit RNA polymerase with near base-pair resolution. Mol. Cell 70, 695-706.e5 (2018).

11. McGuffee, S. R. \& Elcock, A. H. Diffusion, crowding \& protein stability in a dynamic molecular model of the bacterial cytoplasm. PLoS Comput. Biol. 6, e1000694 (2010).

12. Miller, O. L. Jr., Hamkalo, B. A. \& Jr, Thomas,C. A. Visualization of bacterial genes in action. Science 169, 392-395 (1970).

13. Proshkin, S., Rahmouni, A. R., Mironov, A. \& Nudler, E. Cooperation between translating ribosomes and RNA polymerase in transcription elongation. Science 328, 504-508 (2010).
14. Burmann, B. M. et al. A NusE:NusG complex links transcription and translation. Science 328, 501-504 (2010).

15. Demo, G. et al. Structure of RNA polymerase bound to ribosomal 30 S subunit. Elife 6, 1-17 (2017)

16. Fan, H. et al. Transcription-translation coupling: direct interactions of RNA polymerase with ribosomes and ribosomal subunits. Nucleic Acids Res. 45, 11043-11055 (2017).

17. Kohler, R., Mooney, R. A., Mills, D. J., Landick, R. \& Cramer, P. Architecture of a transcribing-translating expressome. Science 356, 194-197 (2017).

18. McGary, K. \& Nudler, E. RNA polymerase and the ribosome: the close relationship. Curr. Opin. Microbiol. 16, 112-117 (2013).

19. Bakshi, S., Siryaporn, A., Goulian, M. \& Weisshaar, J. C. Superresolution imaging of ribosomes and RNA polymerase in live Escherichia coli cells. Mol. Microbiol. 85, 21-38 (2012).

20. Jin, D. J., Cagliero, C. \& Zhou, Y. N. Role of RNA polymerase and transcription in the organization of the bacterial nucleoid. Chem. Rev. 113, 8662-8682 (2013)

21. Campos, M. \& Jacobs-Wagner, C. Cellular organization of the transfer of genetic information. Curr. Opin. Microbiol. 16, 171-176 (2013).

22. Weng, X. \& Xiao, J. Spatial organization of transcription in bacterial cells. Trends Genet. 30, 287-297 (2014)

23. Stracy, M. et al. Live-cell superresolution microscopy reveals the organization of RNA polymerase in the bacterial nucleoid. Proc. Natl Acad. Sci. USA 112 E4390-E4399 (2015).

24. Cabrera, J. E., Cagliero, C., Quan, S., Squires, C. L. \& Jin, D. J. Active transcription of rRNA operons condenses the nucleoid in Escherichia coli: examining the effect of transcription on nucleoid structure in the absence of transertion. J. Bacteriol. 191, 4180-4185 (2009).

25. Raj, A., Peskin, C. S., Tranchina, D., Vargas, D. Y. \& Tyagi, S. Stochastic mRNA synthesis in mammalian cells. PLoS Biol. 4, e309 (2006).

26. So, L. H. et al. General properties of transcriptional time series in Escherichia coli. Nat. Genet. 43, 554-560 (2011).

27. Golding, I., Paulsson, J., Zawilski, S. M. \& Cox, E. C. Real-time kinetics of gene activity in individual bacteria. Cell 123, 1025-1036 (2005).

28. Larson, D. R., Zenklusen, D., Wu, B., Chao, J. A. \& Singer, R. H. Real-time observation of transcription initiation and elongation on an endogenous yeast gene. Science 332, 475-478 (2011)

29. Cabrera, J. E. \& Jin, D. J. The distribution of RNA polymerase in Escherichia coli is dynamic and sensitive to environmental cues. Mol. Microbiol. 50, 1493-1505 (2003).

30. Bakshi, S., Dalrymple, R. M., Li, W., Choi, H. \& Weisshaar, J. C. Partitioning of RNA polymerase activity in live Escherichia coli from analysis of singlemolecule diffusive trajectories. Biophys. J. 105, 2676-2686 (2013).

31. Elf, J., Li, G. W. \& Xie, X. S. Probing transcription factor dynamics at the single-molecule level in a living cell. Science 316, 1191-1194 (2007)

32. Xie, X. S., Choi, P. J., Li, G. W., Lee, N. K. \& Lia, G. Single-molecule approach to molecular biology in living bacterial cells. Annu. Rev. Biophys. 37, 417-444 (2008).

33. Hammar, P. et al. The lac repressor displays facilitated diffusion in living cells Science 336, 1595-1598 (2012).

34. Yang, S. et al. Contribution of RNA polymerase concentration variation to protein expression noise. Nat. Commun. 5, 4761 (2014).

35. Hensel, Z., Weng, X., Lagda, A. C. \& Xiao, J. Transcription-factor-mediated DNA looping probed by high-resolution, single-molecule imaging in live $\mathrm{E}$. coli cells. PLoS Biol. 11, e1001591 (2013).

36. Fisher, J. K. et al. Four-dimensional imaging of E. coli nucleoid organization and dynamics in living cells. Cell 153, 882-895 (2013).

37. Davanloo, P., Rosenberg, A. H., Dunn, J. J. \& Studier, F. W. Cloning and expression of the gene for bacteriophage T7 RNA polymerase. Proc. Natl Acad. Sci. USA 81, 2035-2039 (1984).

38. Tang, G. Q., Roy, R., Ha, T. \& Patel, S. S. Transcription initiation in a singlesubunit RNA polymerase proceeds through DNA scrunching and rotation of the N-terminal subdomains. Mol. Cell 30, 567-577 (2008).

39. Larson, M. H., Greenleaf, W. J., Landick, R. \& Block, S. M. Applied force reveals mechanistic and energetic details of transcription termination. Cell 132, 971-982 (2008).

40. Robinow, C. \& Kellenberger, E. The bacterial nucleoid revisited. Microbiol Rev. 58, 211-232 (1994)

41. Sherratt, D. J. Bacterial chromosome dynamics. Science 301, 780-785 (2003)

42. Woldringh, C. L. The role of co-transcriptional translation and protein translocation (transertion) in bacterial chromosome segregation. Mol. Microbiol. 45, 17-29 (2002).

43. Mondal, J., Bratton, B. P., Li, Y., Yethiraj, A. \& Weisshaar, J. C. Entropy-based mechanism of ribosome-nucleoid segregation in E. coli cells. Biophys. J. 100 2605-2613 (2011)

44. Bakshi, S., Choi, H., Mondal, J. \& Weisshaar, J. C. Time-dependent effects of transcription- and translation-halting drugs on the spatial distributions of the Escherichia coli chromosome and ribosomes. Mol. Microbiol. 94, 871-887 (2014). 
45. Bakshi, S. et al. Nonperturbative imaging of nucleoid morphology in live bacterial cells during an antimicrobial peptide attack. Appl. Environ. Microbiol. 80, 4977-4986 (2014).

46. Sukhodolets, M. V., Garges, S. \& Adhya, S. Ribosomal protein S1 promotes transcriptional cycling. RNA 12, 1505-1513 (2006).

47. Deana, A. \& Belasco, J. G. Lost in translation: the influence of ribosomes on bacterial mRNA decay. Genes Dev. 19, 2526-2533 (2005).

48. Sanamrad, A. et al. Single-particle tracking reveals that free ribosomal subunits are not excluded from the Escherichia coli nucleoid. Proc. Natl Acad. Sci. USA 111, 11413-11418 (2014).

49. Ma, J., Bai, L. \& Wang, M. D. Transcription under torsion. Science 340, 1580-1583 (2013).

50. Chong, S., Chen, C., Ge, H. \& Xie, X. S. Mechanism of transcriptional bursting in bacteria. Cell 158, 314-326 (2014).

51. Dillon, S. C. \& Dorman, C. J. Bacterial nucleoid-associated proteins, nucleoid structure and gene expression. Nat. Rev. Microbiol. 8, 185-195 (2010).

52. Wang, W., Li, G. W., Chen, C., Xie, X. S. \& Zhuang, X. Chromosome organization by a nucleoid-associated protein in live bacteria. Science $\mathbf{3 3 3}$, 1445-1449 (2011)

53. Liu, L. F. \& Wang, J. C. Supercoiling of the DNA template during transcription. Proc. Natl Acad. Sci. USA 84, 7024-7027 (1987).

54. Lavelle, C. Pack, unpack, bend, twist, pull, push: the physical side of gene expression. Curr. Opin. Genet. Dev. 25, 74-84 (2014).

55. Revyakin, A., Ebright, R. H. \& Strick, T. R. Promoter unwinding and promoter clearance by RNA polymerase: detection by single-molecule DNA nanomanipulation. Proc. Natl Acad. Sci. USA 101, 4776-4780 (2004).

56. van Loenhout, M. T., de Grunt, M. V. \& Dekker, C. Dynamics of DNA supercoils. Science 338, 94-97 (2012).

57. Moulin, L., Rahmouni, A. R. \& Boccard, F. Topological insulators inhibit diffusion of transcription-induced positive supercoils in the chromosome of Escherichia coli. Mol. Microbiol. 55, 601-610 (2005).

58. Skinner, S. O., Sepulveda, L. A., Xu, H. \& Golding, I. Measuring mRNA copy number in individual Escherichia coli cells using single-molecule fluorescent in situ hybridization. Nat. Protoc. 8, 1100-1113 (2013).

\section{Acknowledgements}

We thank J. Xiao for providing the plasmid (pACL08) and P. Choi for helpful discussion. This work was supported by the grant from Midcareer Research Program (NRF-

2017R1A2B3010309) of the National Research Foundation of Korea.

\section{Author contributions}

S.Y., A.H.G. and N.K.L. designed the experiments; S.Y., S.K. and N.K.L. wrote the manuscript; S.Y. performed the microscopy experiments. S.Y. and S.K. performed the image analyses and constructed the bacterial strains. S.K. performed real-time RT-PCR experiments. D.-K.K., H.J.A. and J.B.S. helped measurements and analysis. H.J.A. performed the simulation. N.K.L. supervised the project.

\section{Competing interests}

The authors declare no competing interests.

\section{Additional information}

Supplementary information is available for this paper at https://doi.org/10.1038/s41467019-13152-y.

Correspondence and requests for materials should be addressed to N.K.L.

Peer review information Nature Communications thanks the anonymous reviewers for their contribution to the peer review of this work. Peer reviewer reports are available.

Reprints and permission information is available at http://www.nature.com/reprints

Publisher's note Springer Nature remains neutral with regard to jurisdictional claims in published maps and institutional affiliations.

(c) (i) Open Access This article is licensed under a Creative Commons Attribution 4.0 International License, which permits use, sharing, adaptation, distribution and reproduction in any medium or format, as long as you give appropriate credit to the original author(s) and the source, provide a link to the Creative Commons license, and indicate if changes were made. The images or other third party material in this article are included in the article's Creative Commons license, unless indicated otherwise in a credit line to the material. If material is not included in the article's Creative Commons license and your intended use is not permitted by statutory regulation or exceeds the permitted use, you will need to obtain permission directly from the copyright holder. To view a copy of this license, visit http://creativecommons.org/ licenses/by/4.0/.

(C) The Author(s) 2019 